\title{
Effect of soil stabilized by cement on dynamic response of machine foundations
}

\author{
Saad Al-Wakel ${ }^{1, *}$, and Ahmed Abdulrasool ${ }^{1}$ \\ ${ }^{1}$ Building and Construction Engineering Department, University of Technology, Baghdad, Iraq
}

\begin{abstract}
Machine foundations require significant attention from designers. The main goal of the design of machine foundation is to limit the amplitude displacement and not disturb the people who work near the machine. In some cases, if the design of machine foundations does not satisfy the acceptable value of the dynamic response (such as maximum amplitude of displacement), the stabilization of soil under the machine foundation may be used to decrease the amplitude of displacement. This paper outlines effect of stabilized soil under the foundation by cement on the displacement response of machine foundations. Three-dimensional analyses by using finite element method are carried out to investigate the effect of depth of stabilized layer with different percentage of cement content on the dynamic response of the machine foundation. In addition, the effect of area stabilized by cement material on the dynamic response of machine foundation is investigated. The results shown that, the dynamic response of machine foundations generally decreases with increasing the depth of soil layer stabilized with cement. A significant decrease in the displacement of machine foundations is occurred for the stabilized soil layer with a depth of two times of the width of foundation, and the optimum percentage of cement for stabilizing is $6 \%$.
\end{abstract}

\section{Introduction}

In principle, machine foundations should be designed so that the dynamic forces of machine are transmitted to the soil through the foundation in a way that all kinds of harmful effects are eliminated. The dynamic response of the supporting structure is critical for the in-service stability and safety of machine foundations. In the previous, the simple calculation methods were used, always involving the static loads multiplication by the factor of dynamic. The actual safety factor is not knowledge due to the result being treated as an increased static load. Because of this doubt, the value of dynamic factor was often too high; the exercise showed that the harmful deformations results can be occurred during operation in spite of using such excessive factors. This required a deeper scientific dynamic investigation. Due to the development of machines, a study for more detailed was became urgent. Because increased energy demand around the world in recent years, the control to dynamic response of machine foundations is very important.

Experimental studies on the dynamic behaviour of surface and embedded foundations have been reported by many investigators [1-9] and many others studied the vertical mode of vibration of surface footings, while [1011] and others studied the vertical mode of vibration of embedded foundations.

Some experimental studies have also been conducted on tensional and sliding modes of vibration [12-14].
All the experimental work cited above has been performed on model or small prototype footings in the field or in the laboratory in soil bins with dimensions in the range of a few feet. The largest size foundations tested in the field were generally foundations for onestory buildings, electric towers, or machine foundations, The largest model foundations used in laboratory tests were comparable with some machine foundations, but in general were about $1 / 10$ to $1 / 5$ of prototype foundations for larger structures such as buildings with several stories.

Some experimental tests of small and rigid model structures of few inches in height, of various shapes and soil densities, have been run on shaking table to study the effect of geometry, soil and embedment on response [15].

The goal of this study is considering the effect of soil stabilized by cement on dynamic response of machine foundations by using three-dimensional finite element modelling.

\section{Types of machine foundations}

The types of Machine foundations based on the shapes of structural as follows (see, Fig. 1) [16]

1. Rigid foundations (Block type)

2. Caisson type or Box

3. Type of wall

4. Type of framed

5. Type flexible or Non-rigid

Corresponding author: saadfaik231@yahoo.com 
In this study, the Machine foundation is considered a rigid foundation.

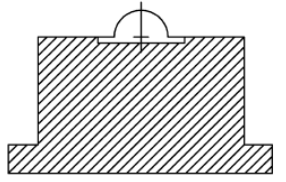

(a) Block-type (rigid)

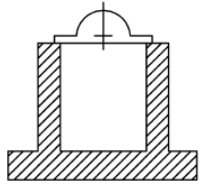

(c) Wall-type

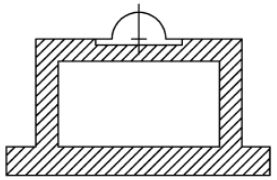

(b) Box-type

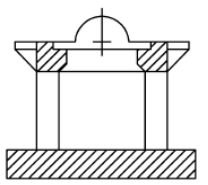

(d) Framed-type

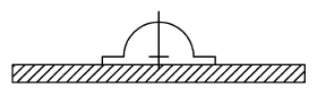

(e) Flexible-type

Fig. 1 Common types of machine foundations.

\section{Equation of motion of the dynamic system}

The general equation of motion for a system is given by Zienkiewicz and Taylor [17]:

$$
[M]\{\ddot{u}\}+[C]\{\dot{u}\}+[K]\{u\}=\{F\}
$$

where:

$[\boldsymbol{M}]=$ matrix of mass,

$[\boldsymbol{C}]=$ matrix of damping,

$[\boldsymbol{K}]=$ matrix of stiffness,

$\{\ddot{\boldsymbol{u}}\}=$ nodal acceleration vector,

$\{\dot{\boldsymbol{u}}\}=$ nodal velocity vector,

$\{\boldsymbol{u}\}=$ nodal displacement vector, and

$\{\boldsymbol{F}\}=$ applied load vector.

\section{Harmonic excitation of the dynamic force}

The dynamic behaviour of foundation plays an important role in providing normal operating conditions for the supported turbo-machine. In this study, the source of the dynamic forces is from a gas turbine machine. The dynamic forces in the vertical direction perpendicular to the longitudinal rotation axis is

$$
F(t)=P \sin \omega t
$$

where:

$$
P=m e \omega^{2}
$$

$m=$ proportional part of rotating mass,

$e=$ eccentricity of mass,

$t=$ time,

$\omega=$ circular operating frequency of the machine $(2 \pi f)$.

$f=$ operating frequency.
The maximum amplitude of the dynamic force is $43 \mathrm{kN}$, the circular operating frequency of the machine 314 $\mathrm{red} / \mathrm{sec}(f=50 \mathrm{~Hz})$ at the nominal turbine speed.

\section{Finite element analysis}

A three-dimensional finite element method which is implemented in OpenSees program (Open System for Earthquake Engineering Simulation) [18] is used to analyze the dynamic response of the turbine machine foundation under the effect of harmonic excitation of vertical load. The objective is to investigate the effective depth for the improvement layer under machine foundation, and the effect of the cement percentage to stabilize the soil on the dynamic response of machine foundations.

A concrete foundation is placed at the centre of the model and the dimensions of the foundation are $6 \times 6 \times$ $0.5 \mathrm{~m}$. The behaviour of the material of the foundation is assumed linear elastic. Table 1 shows the parameters of the concrete material. The soil boundaries are taken as $212 \mathrm{~m}$ wide, $212 \mathrm{~m}$ length, and $42 \mathrm{~m}$ depth. A linear elastic model is assumed for soil behaviour. The soil properties are assumed uniform throughout the depth of the layer as shown in Table 2.

Table 1. Parameters of the concrete material.

\begin{tabular}{|c|c|c|}
\hline Properties & Value & Units \\
\hline Modulus of elasticity (E) & 25742960 & $\mathrm{kN} / \mathrm{m}^{2}$ \\
\hline Poisson's ratio (v) & 0.2 & - \\
\hline $\begin{array}{c}\text { Compressive strength of concrete } \\
\left(f^{\prime} c\right)\end{array}$ & 30 & $\mathrm{MPa}$ \\
\hline Unit weight of concrete & 24 & $\mathrm{kN} / \mathrm{m}^{3}$ \\
\hline
\end{tabular}

Table 2. Soil properties.

\begin{tabular}{|c|c|c|}
\hline Properties & Value & Units \\
\hline Modulus of elasticity $(\mathrm{E})$ & 10000 & $\mathrm{kN} / \mathrm{m}^{2}$ \\
\hline Poisson's ratio $(\mathrm{v})$ & 0.35 & - \\
\hline Unit weight of dry soil $(\gamma)$ & 14.5 & $\mathrm{kN} / \mathrm{m}^{3}$ \\
\hline
\end{tabular}

In this analysis, eight nodes brick element are used. The brick element has eight nodes at the corners with three degrees of freedom for each node. The elementary boundaries with zero-displacement conditions are used at the boundary of the soil model, so that the bottom of the soil is supposed to be fixed. The displacement in $\mathrm{X}$ directions for the nodes at the boundary in $\mathrm{Y}-\mathrm{Z}$ planes is fixed; as well the displacement in $Y$-directions for the nodes at the boundary in $\mathrm{X}-\mathrm{Z}$ planes is constraint. The model of the soil under the machine foundation is assumed homogenous isotropic elastic material due to the small amplitude of vibrations. 
The three-dimensional finite element model and the cross-section of the model are shown in Figs 2 and 3, respectively. At the top central point (A) of the foundation (see, Fig. 2), the vertical load is applied and the amplitude of displacements are measured at the same point. In this study, the time period of the analysis is $(1000 \mathrm{sec})$ with time step $(\Delta \mathrm{t}=0.0043 \mathrm{sec})$. The Newmark method is used for the time integration [19].

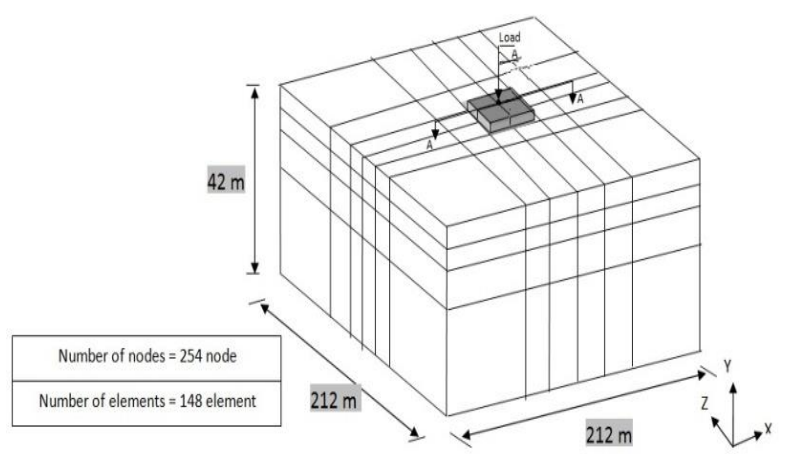

Fig. 2 The mesh of 3D finite element model.

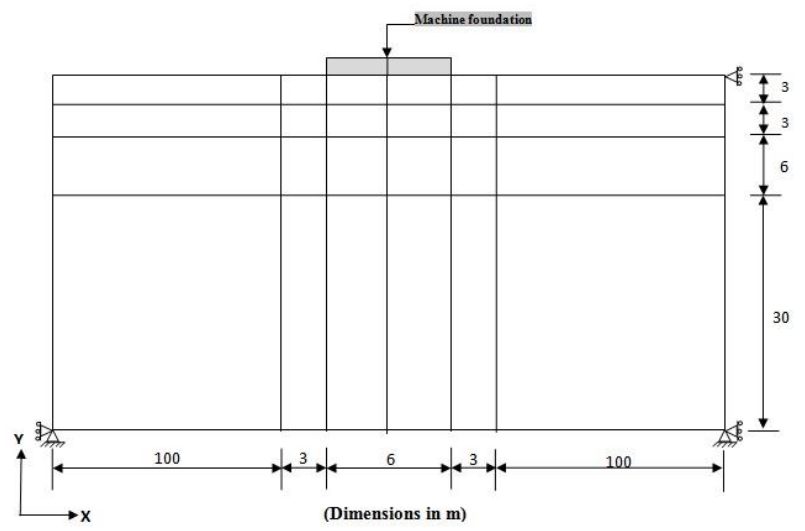

\section{Effect of cement percentage to stabilize the soil on dynamic response}

In this part, the analysis is conducted to determine the vertical displacement of machine foundation that rests on soil stabilized with different percentage of cement $(2,4$, 6,8 , and 10).

As a first stage, the thickness of the improved layer for all cases is considered for a depth equal to $2 \mathrm{~B}$. The Poisson's ratio, modulus of elasticity and unit weight of dry sand is obtained from previous study [20]. Table 3 shows the soil properties with different percentage of cement.

The relationships between time and amplitude of vertical displacement for the machine foundation constructed on a sand layer stabilized with different percentage of cement is depict in Fig. 4.

Table 3. Properties of sand with different percentage of cement.

\begin{tabular}{|c|c|c|c|}
\hline $\begin{array}{c}\text { Cement } \\
(\%)\end{array}$ & $\begin{array}{c}\text { Modulus of } \\
\text { elasticity } \\
(\mathbf{E}) \mathbf{k N} / \mathbf{m}^{2}\end{array}$ & $\begin{array}{c}\text { Poisson's } \\
\text { ratio }(\boldsymbol{v})\end{array}$ & $\begin{array}{c}\text { Unit weight } \\
\text { of dry soil }(\gamma) \\
\mathbf{k N} / \mathbf{m}^{3}\end{array}$ \\
\hline 2 & 10906.08 & 0.34 & 19.3 \\
\hline 4 & 11673.09 & 0.33 & 20.48 \\
\hline 6 & 77255.67 & 0.30 & 20.43 \\
\hline 8 & 246080.2 & 0.28 & 21.03 \\
\hline 10 & 849982.9 & 0.24 & 20.50 \\
\hline
\end{tabular}

Fig. 5 shows the relationship between the maximum amplitude of displacement of machine foundation and the percent of cement used to stabilize the soil.

Fig. 3 Cross-section A-A of machine foundations and soil.
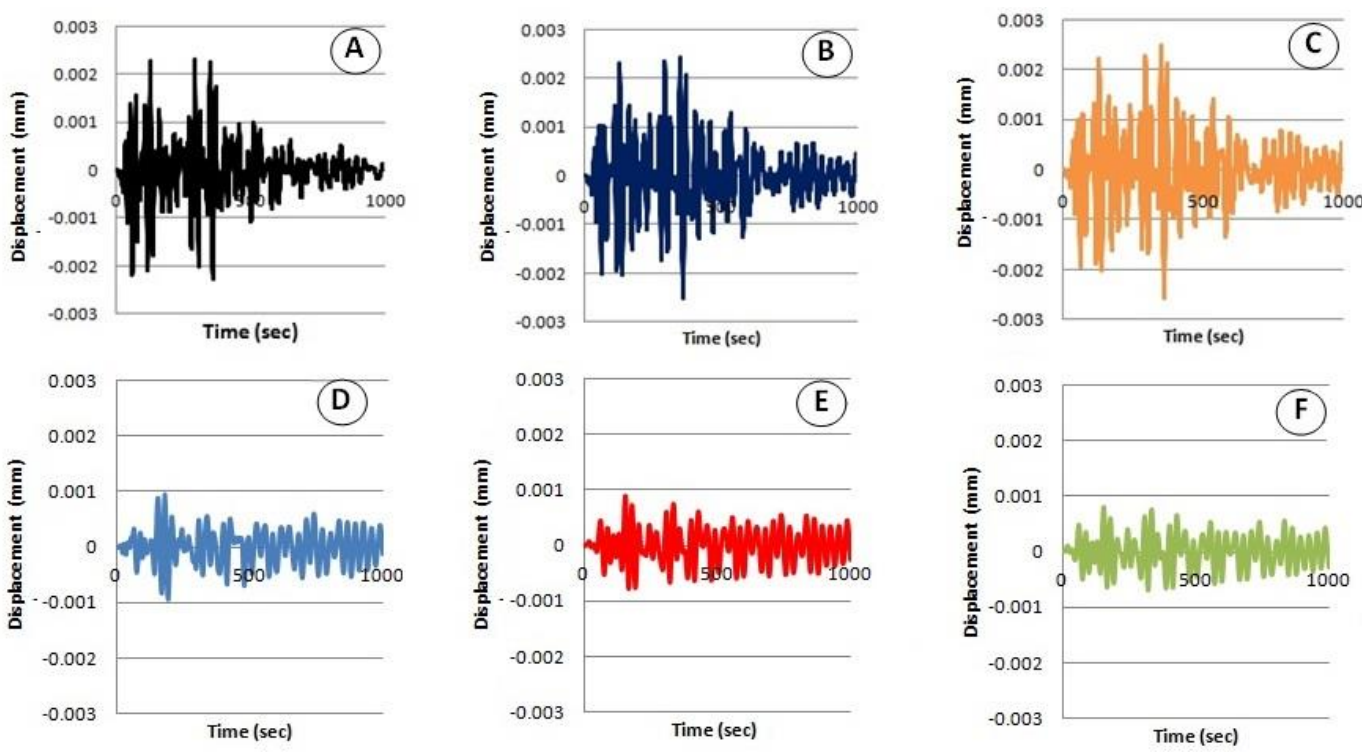

Fig. 4 Predicted displacement at point A of the foundation rests on stabilized layer at depth $2 \mathrm{~B}$ with different percentage of cement (A) Soil without treatment; (B) $2 \%$ cement; (C) $4 \%$ cement; (D) $6 \%$ cement; (E) $8 \%$ cement; (F) 10\% cement. 


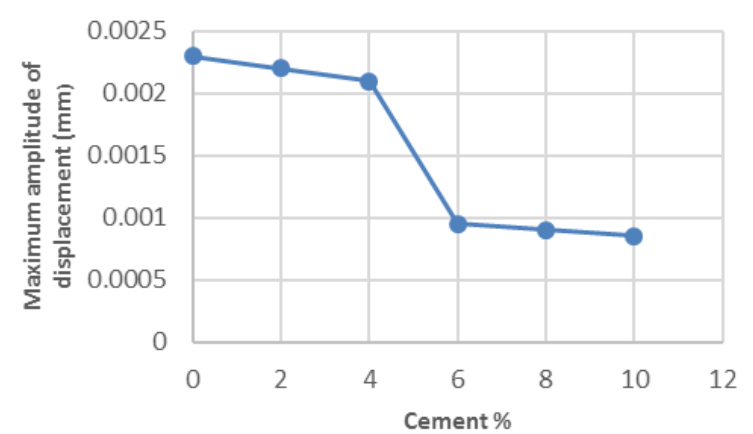

Fig. 5 Maximum amplitude of displacement vs. cement percentages.

From Fig. 5 it can be stated that, the displacement of the machine foundation decreases with increasing of cement percent used to stabilize the underlying soil and the optimum value is $6 \%$.

\section{The effect of stabilized layer depth by cement on the dynamic response}

The analysis is performed to estimate the optimum thickness of the layer that stabilized with $6 \%$ cement for the machine foundation purposes. In this analysis, only the thickness of the stabilized layer is changed with different values of $(0.5 \mathrm{~B}, 1 \mathrm{~B}$ and $2 \mathrm{~B})$. The results of the vertical displacement response are presented in Fig. 6.

Fig.7 shows the relationship between the maximum amplitude of displacement of machine foundation and the depth of improvement layer of the soil.

From Fig. 7 it can be seen that the vertical displacement decreases with increase of the thickness of the layer that is stabilized by cement due to the increasing in stiffness of the system (soil-foundation), and the optimum depth for improving the soil is $1 \mathrm{~B}$.
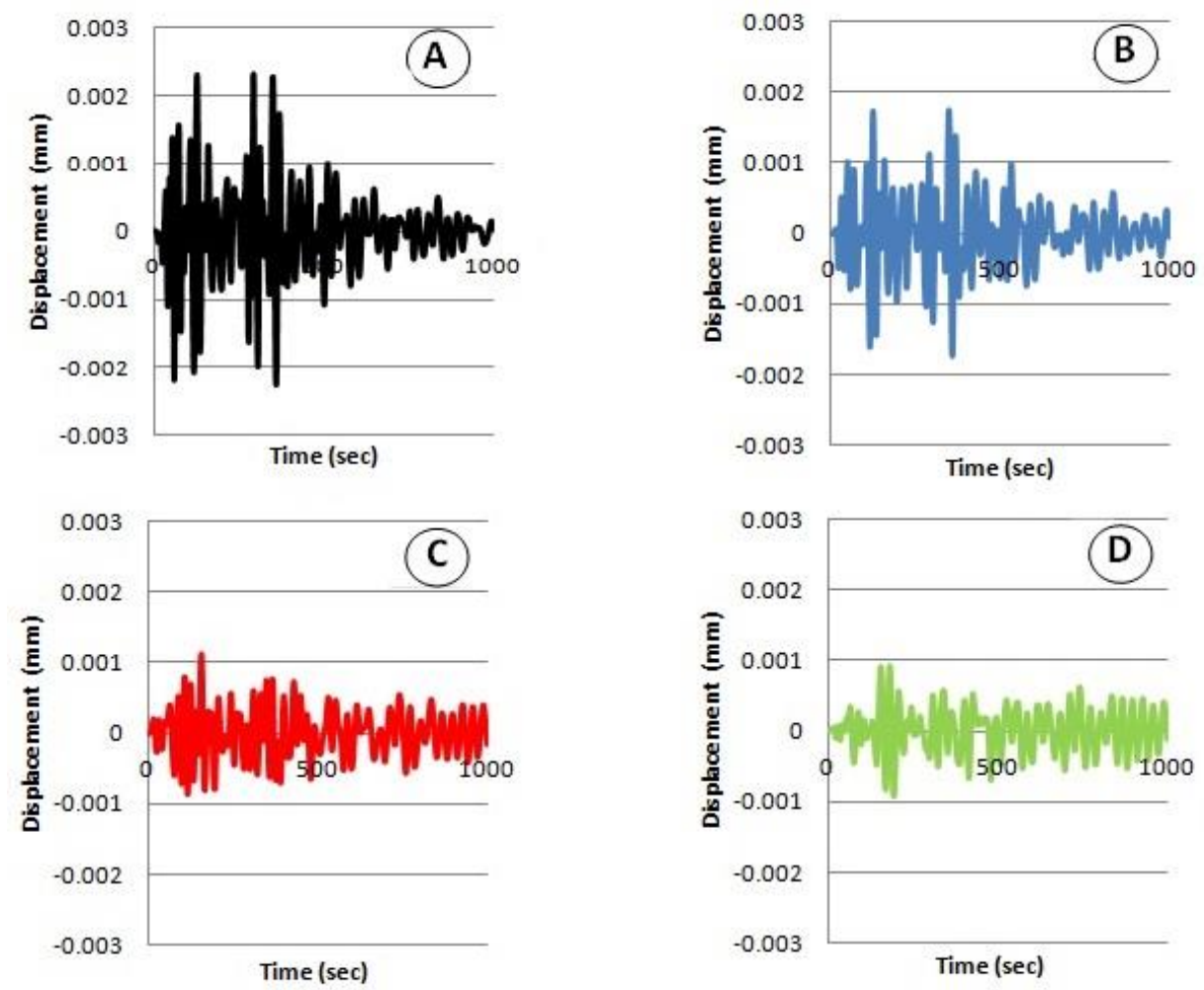

Fig. 6 Predicted displacement at point $A$ on foundation with different depth of layer stabilized with $6 \%$ cement: (A) Soil without treatment (B) $0.5 \mathrm{~B}$ (C) 1B (D) $2 \mathrm{~B}$. 


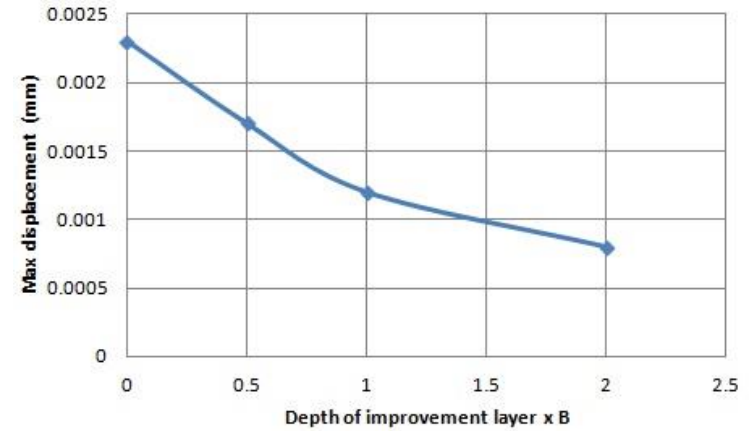

Fig. 7 Maximum amplitude of displacement vs. depth of improvement layer

\section{Conclusions}

1. Soil stabilization by cement for the soil under machine foundations can be considered as a successful future technique to decrease the displacement of the machine.

2. The maximum amplitude of displacement is affected by the percent cement that used to stabilize the soil due to increasing the stiffness of the foundation, and the optimum value of cement is $6 \%$.

3. The increase in depth layer of the soil improvement with cement leads to a decrease in the displacement response of the machine foundation gradually. However, the depth of improvement upto $0.25 \mathrm{~B}$ will lead to decrease the dynamic response by $25 \%$.

\section{References}

1. T. K. Al-Azawi, R. K. Al-Azawi, Z. K. AlJaberi, Eng. J., University of Baghdad 12, 429443 (2006)

2. S. F. A. Al-Wakel, Eng. \& Tech. J. 31, 14471458 (2013)

3. S. F. A. Al-Wakel, M. R. Mahmoud, A. S. Abdulrasool, Eng. J., University of Baghdad 20, 48-61 (2014)

4. K. H. II Stokoe, (PhD Thesis, University of Michigan, 1972)

5. S. M. Erden, (PhD Thesis, University of Massachusetts, 1974)

6. S. N. Varadhi, S. K. Saxena, Geotech. Eng. J. ASCE 106, 1121-1139 (1980)

7. S. F. A. Al-Wakel, M. R. Al-Qaissy, A. S. Abdulrasool, Eng. \& Tech. J. 33, 1038-1048 (2015)

8. S. F. A. Al-Wakel, M. Y. Fattah, H. H. Karim, Eng. \& Tech. J. 29, 2189-2201 (2011)

9. A. S. Abdulrasool, (MSc Dissertation, University of Technology, Iraq, 2012)

10. M. Novak, Soil Mech. \& Found. J. ASCE 96, 337-361 (1970)

11. B. N. Gupta, Geotechnique J. 22, 129-137 (1972)

12. H. R. Sreekantiah, Geotech. Eng. J. ASCE 108, 905-917 (1982)
13. A. N. Lin, Earthquake Engineering Research Laboratory (EERL) 82, 1(1982)

14. R. Henake, F. E. Richart, Jr., R. D. Woods, Geotech. Eng. J. ASCE 109, 72-88 (1983)

15. A. H. Hadjian, G. E. Haward, C. B. Smith, Proceedings of the Third International Conference on SMIRT, K2/5 (1975)

16. N. S. V. Kameswara Rao, "Foundation Design: Theory and Practice," John Wiley \& Sons (Asia) Pte Ltd, Singapore, 2011.

17. O.C. Zienkiewicz, R. L. Taylor, "The Finite Element Method," McGraw-Hill, London, UK, 2005.

18. Open System for Earthquake Engineering Simulation (OpenSees) Manual, 2005.

19. M.G. Katona, O.C. Zienkiewicz, International J. for Numerical Methods in Eng. 21, 1345-1359 (1985)

20. Z. W. S. Abbawi, K. Y. H. AL-Soudany, Eng. \& Tech. J. 33, 1857-1875 (2015) 